\title{
Using GIS for Retail Location Assessment at Jeddah City
}

\author{
Abdulkader A Murad \\ Faculty of Environmental Design, King Abdulaziz University, P O Box 80210, Jeddah- 21589, Saudi Arabia
}

\begin{abstract}
GIS software has different useful tools that can be used for sites, demographic and competitive analysis. These tools enable retail and market researchers to find solutions related to many retail planning issues. The aim of this paper is to use Geographical Information Systems (GIS) for retail location assessment of two retail centers called Al-Dawly and Al-Mahmal centers located at Jeddah city, Saudi Arabia. The first part of the paper presents a review about retail centers classification and about GIS applications in retail planning field. The second part of the paper discuss the outputs of the created application which include a- defining retail catchment area, b- building retail demand profile, and c- analyzing retail catchment area. The results of this application can be used by retail planners for evaluating retail centers location and for identifying the extent of retail market
\end{abstract}

Keywords-Retail Planning; Retail Catchment Area; GIS; Market Penetration; Drive Time

\section{INTRODUCTION}

One of the main noticeable features of Jeddah city is related to the rapid growth and expansion in retail facilities. Every city district has different types of retail centers. Some of these centers are small and specialized in certain goods or products e.g. mobile phone centers, and others are large retail centers e.g. Hera or Altahlia centers which have various types of retail facilities. All of these centers are faced today with many important issues related to their existing or potential demand. These issues include location of customers, income level of people or clients living within retail center catchment area, location of competitors and their related demand and the level of retail center attractiveness. In addition to these issues, retail developers face different strategic and operating decisions, ranging from initial site selection to mall configuration and tenant mix to managing lease receivables. These decisions can be facilitated by relevant timely accessible information. This indicates that there is a great need to use information technologies for handling this information. One of the most useful technologies that can handle and manipulate retail data is known as Geographical Information Systems (GIS) that are defined as computerized based systems that provides different tools for handling and manipulating spatial data. The use of GIS and spatial modeling in applied retail location analysis is a relatively new phenomenon [1]. While GIS technology dates to the 1960s, most early applications were associated with natural resources, municipal/ public service and military applications [2]. Birkin et al, 1996 [1], have identified five main retail analytical techniques that can be covered with GIS. These are called: trial and error, analogue techniques, regression techniques, catchment area analysis and mathematical models that include spatial interaction models, location allocation and optimization models. Some of these techniques are explored by GIS based studies [1,2,3,4,and 5], . This paper is concentrated on applying GIS at one of these retail analytical techniques which is called the catchment area analysis. This technique is defined as abroad set of procedures aimed to measure more objectively the size of existing centers (and hence their potential) and to understand the break down of their catchment areas in terms of population structure [5]. At first, the paper will review the size and the extent of existing retail centers catchment area and then will focus on applying GIS for defining and analysis catchment area of two retail centers called Al-Dawly and Al-Mahmal center at Jeddah city, Saudi Arabia. Two main types of retail catchment areas are produced which are called the primary catchment area, and the drive time catchment area. The former is created based on customers' location, and the latter is produced based on the expected drive time to the selected center. Each one of these catchement areas is created to support retail developers and planners in understanding the spatial extent of their center's catchment area, and also to help them in deciding upon the performance of their retail center too.

\section{BACKGROUND}

\section{A. Types of Retail Centres}

There are two basic methods of classifying retail centres, and they are based on either the types of goods and shops included or based on the trade area [6]. In the forms method, retail centres are divided into two groups, those selling convenience goods such as food items and toiletries, and those selling durables, such as clothing, furniture and household appliances. The latter method of retail centers classification produces the following types of centres:

1) Neighbourhood Centre: The function of neighborhood centre is to provide a range of convenience goods and personal services, for the day to day needs. The assumed catchment population is 2500 to 40,000 people within a six minute drive times and it is generally assumed that consumers visit their nearest centre [7]. The location of neighbourhood centre should be embedded in residential areas. However, commercial developers prepare sites at intersections on major roads, which are on the edge of residential blocks. The average area for this type of centres is 40,000 to 50,000 square feet [8].

2) Community Centre: This type of retail centres offers shoppers greater depth and range of merchandize-assortments 
in clothing sizes, styles, colors, and prices than does a neighbourhood centre. The community center serves from 40,000 to 150,000 people, and has a site area of 4-12 ha [7]. Community centres have convenience goods more than neighborhood centres, but at the same time they have durable goods less than regional centres.

3) Regional Centre: The third type of retail centres provides all forms of general merchandise, apparel and furniture, and almost all those retail facilities available in the town centre. The size of regional centres varies dramatically from 10 acres for a multilevel centre to over 100 acres for a large single level centre (ibid). These centres comprised a great number and variety of shops selling convenience goods and competing with one another by low prices and range of assortment [9].

The above retail centre hierarchy represents a general frame for classifying retail centres. However, there are other retail centre types which can be added to those three classes e.g. Ancillary centres, and specialty centres.

\section{B. Existing Retail Catchment}

The aim of this part of the paper is to present several existing retail centers and identifies their catchment areas. This is considered as a literature background that at the end will conclude with a realistic definition of retail centers catchment area. This review covers some retail centers that are located at different European countries. In general, retail centers can be classified into three groups based on their physical sizes. These are called large, medium and small retail centers.

\section{1) Large retail centers}

The first type of retail center classification is known as large retail centers. These are characterized with larger catchment population $(800,000$ person) and with the availability of large mixed-use schemes. Tres Aguas center at Madrid, Spain, is an example of retail centers that falls within this group. It provides a total of 46,000 sqm GLA (Gross Leasable Area) for its 800,000 person total catchment area and provides 3200 car parking spaces for its visitors [10]. Carre senart at France is another example of large retail centers. It is one of the largest shopping centers of its kind in France located $35 \mathrm{~km}$ south west of Paris. It enjoys a total catchment population of 800,000 and has 130 shops with $65,000 \mathrm{sqm}$ GLA and provides 4700 car parking spaces for its customers that are summed by 4.3 million shoppers on its first 4 trading months [11] . Bonaire retail center at Valencia - Spain is a third example of this group. It serves a total catchment area of 1.1 million inhabitants within 20-minute drive and it is considered as the biggest $(135,000$ sqm GLA) retail development of Southern Europe [12] . Looking at those three large centers, it can be said that every large retail center should serve a minimum catchment population of 800,000 people and should provide at least 4000 -car parking spaces.

\section{2) Medium-sized retail center}

The second type of retail centers is called medium-sized centers. These centers are very important in any city because they can be distributed at different areas of the city and create remarkable impacts on land uses and transportation network too. For example, Spandan Arcaden is a medium sized retail center at Berlin, Germany, located to revitalize the center of Spandau by bringing modern retail space and recreational facilities within easy reach of the historic town center and residents of West Berlin. This center has a catchment population of 230,000 within 15 minutes drive time and provides 125 shops for its customers [13]. The second similar example is Altmarkt Galerie, which is located in the heart of Dresden, the historical capital city of Saxony in the south east of Germany. It has a primary catchment population of some 180,000 person, 26,000 sqm GLA, 107 shops and 500 car parking spaces [14] . This center is another example showing how medium sized retail centers can be integrated into historical city center life without loosing customer comfort or retailing efficiency. Fiumara center in Italy is a third example of this type of retail centers situated in the historical docklands area just west of Genoa city with a catchment area of approximately, 180,000 inhabitants living within 30 minutes drive. It consists of approximately 25,000-sqm retail GLA with over 100 shop units and has 2,200 car parking spaces [15] . This center is another good example of a development that has successfully integrates both the old and the new future of Genoa city.

In comparing between the above examples of medium sized retail centers, it can be said that these centers can be located at old or declined areas to increase the growth of such areas, and they serve an average catchment of 200,000 person living within 20 minutes drive and has at least 100 shops.

\section{3) Small retail centers}

Small retail centers are another interested retail types that are located at or close to residential districts. For example, Les passages center is located southwest of Paris and provides retail services for a total catchment area of 150,000 inhabitants. It has 21,700 sqm GLA (56 shop units) and allows access to car parking with about 600 spaces [16] . One of the other features of this type of retail centers is that they can be integrated easily with ribbon retail streets that are mainly fond at city center or along main road. The second example of this type of retail centers is found at Espace Jaures center at Brest town in France. This center has 30 shops with a total 14,000 sqm GLA, located on a shopping street with a 400 car parking spaces [17].

Accordingly, it can be concluded from this review that small retail centers are characterized with about 50 shops and catchment population of 150,000 people and provide about 15,000 sqm GLA for retail activities.

\section{GIS and its development in retail planning}

The objective of retail planning can be summarized as the provision of the right amount of land for retailing in the right place. To achieve this objective, retail planners use catchment area and market penetration techniques as analytical methods for retail assessment purposes. The catchment area can be used as a descriptive method to observe the degree of centre coverage, to identify areas of under-representation as obvious gaps in the map, and thus to spit potential new sites [18]. A market penetration approach, on the other hand, is more relevant to a single operating retail outlet that which to increase its sales, either by extending its trade area in space or 
by attracting a greater proportion of households within the existing trade area [8]. These two techniques can be wellperformed using GIS analytical functions. One of the main questions that retail planners ask is about where customers live. The answer for this question can be used for promotional purposes. GIS has the capability of transforming retail attribute data that contain addressing into a point feature map that can be used for defining the spatial distribution of such customers. Another question that can be asked by customers is about the location of the nearest retail centre. GIS can give answers to those customers through the Internet and the result will be a map showing the required facilities. A more sophisticated type of spatial query involving defining an area of interest rather than simplest location of a facility. For example, finding customers that are at a defined distance from retail centre. The GIS spatial query function can be used to define the required area. Retailers typically keep a customer database made up of POS (point of sale) data from private label credit cards or ZIP code information. The sales transactions are then tied to the store number where the purchase was made. GIS software geocodes this information and maps where those customers are. A retailer can see its total sales by ZIP code or sales territory, which creates spatial patterns. It can link customer data to additional data like lifestyle clusters and determine the buying behavior of a specific demographic based on those patterns [19]. The user can query the database to learn more information about customers, such as the last time they shopped, what they bought, and with what frequency.

There are also another GIS functions that are useful in retial planning studies and they include Near, Buffer and Thiessen functions. The Near command can calculate the shortest distance between a point and a line [20]. Such function can be used to obtain the basic measurements, such as the size of built-up areas and the travel to retail distances that may be required for further spatial and statistical analysis [21]. The Buffer function can be used to define the retail centre catchment area based on a defined distance from retail centre. Meanwhile Thiessen function can be applied on a point data such as location of customers to have polygon feature data where the area inside the polygon is closer to the point than to any other point. These various GIS functions were used at several retail planning applications. The followings are examples of such applications:

\section{1) Products Delivery}

One of the important tasks in retail planning is related to the delivery of commercial products to the relevant customers. This task is a challanging one because several factors determine how fast the product can be delivered. These include road traffic, mode of transportation and quality of products. In addition to these factors, the company's delivery system can play major role in the success of delivery products within the agreed period of time. In order to work with these different issues and factors, retail officers benefit from using GIS technology in their product delivers routes. For example, Minute Man Company, uses GIS for products delivery at the USA. It uses GIS and Global Position Systems (GPS) to point out the location of delivery customers, select the most appropriate vehicle type located closest to the collection point and provides a displayed map to driver showing the most efficient path to delivery of pick up point [22]. There are several GIS softwares that can handle the product delivers issue for retail companies. For example the Maps Guide is used in Germany to calculate optimum routes on defined rules. The Autoroute is another software used in the UK for defining routes between many specific locations [23]. Retail planners can use these GIS modules to make sure that their service is delivered at the minimum periods of time.

\section{2) Location of retail stores:}

Most if not all of retail companies work hard to decide on where to open a new branch or a new store. This decision is difficult to achieve based on the analogue technique which that uses paper maps and squatter information. The best solution for this kind of scenario is to use GIS as a decision support system for finding the best new retail location. An example of this approach is founding Miracle supermarket in Ontario, Canada. In this retail application, GIS is used for assessment of new sites, and the processing of customer survey for existing stores (ibid) in this example, trade areas were defined based on distances from existing stores. Another GIS application is found at the IKEA GIS project in Canada which is made to select new retail sites based on a) a minimum population base of more than one million living within a one hour drive time, b) in expressive land, and c) proximity of a major round [24]. In addition to deciding on where to open new store, the IKEA GIS is used to study customers' characteristics based on the collected survey data.

In addition to the previous applications, there have been considerable activities among many worldwide retailers in the last few years in terms of their adoption of GIS. Marks \& Spencer, Tesco, Boots, Asda, BHs, and Gateway are examples of major UK retailers that have applied GIS for their stores development and planning [25]. For those applications, Geodemographics and life style data are considered as the main data input sources. Geodemographics is defined by Sleight 1995, as the analysis of demographic data, which may be derived from census of population data or from large-scale survey, by units of geography. Geodemographic systems are useful for those retailers who have customers concentrated in certain geodemographic segments and are keen to find locations of the right type for their product [19]. Retailers can use this type of data to monitor the patterns of demand variation between different geodemographic groups. However, the main problem lies in the linkage process, whereby individual respondents are ascribed a geodemographic characteristics on the basis of the area they live rather than of the type of person that they are (ibid). The second main source of data for retail applications is known as lifestyle data which is a rich source of detailed information that go beyond the traditional census data such as occupation or age, to ask about behaviors, hobbies and performances [26]. For example, the largest UK's life style database has information on over 10 million households and contains a detailed profile of the British at work and play including consumption and shopping habits, leisure activities, media usage, personal finance and many other life style indicators (ibid). Geodemographics and lifestyle data have been used in GIS applications in two main ways. The first one is to use the data for identifying areas 
having a high proportion of inhabitants who are seen as desirable from the points of view of a retail product or service. While the second method of using these data with GIS is found where users identify demand profile and then derive a measure of potential within specific areas.

\section{GIS tools for retail studies}

GIS softwares have different useful tools that can be used for sites, demographic and competitive analysis. These tools enable retail and market researchers to find solutions related to retail issues such as:

- Performing customer or store prospecting

- Defining customer-based or store trade areas

- Finding best retail location

- Conducting market penetration analysis

- Creating gravity models and

- Performing drive-time analysis

All of the above retail analysis issues can be handled in GIS using various types of tools and functions. Some of these tools and functions are going to be discussed at this section.

\section{1) Data query and display}

The simplest GIS tool that can be used at every retail GIS application is related to displaying and queering spatial and attribute data. For example, ArcGIS software has several functions that can be used for data query and display. This software can display attributes in relation to points, lines or polygons which is known as thematic mapping [22]. Retailers can use thematic mapping technique to present any collection of tabular data such as the numbers people within a 30-minute drive time from a selected retail center. Data query tools in GIS can be applied on a single attribute field such as number of retail customers, or on a multiple attribute data field such as retail demand, and retail supply. Retailers can perform their needed spatial query and see the results of that query on the study area map. For example, they could use the mouse or other pointing device at the place of interest on a map and then GIS will search the database and show the data about the selected location. If a multiple query searching is required at any retail data set, spatial features can be selected through logical operations that deal directly with the database and allow the user to identify and select features by a specific set of Criteria. For example, finding all parcels that are having greater than 10,000 customers of certain retail center. Retail database can be displayed in GIS in different ways depending on the attribute types of that data. For example, the unique value technique can be used to display string attribute data, meanwhile the data classification procedure can be applied on numerical data. The unique value function lets the user to assign a unique symbol to each unique value of the attribute. With this type of GIS functions, retailers can identify how different types of features are located with respect to each other and their relative frequency and distribution [27].

The second useful GIS function related to data display is related to drawing quantities of features by graduated color or graduated symbols. This function is considered, as another effective was to visualize numerical attributes of continuous data such population size, temperature or elevation. Most of GIS softwares (e.g. ArcGIS software) have separate modules for displaying and visualization geographical data (such as retail demand distribution) in $3 \mathrm{D}$ views. These modules are useful for viewing retail data from multiple viewpoint using different viewers [28].

\section{2) Data analysis and manipulation}

One of the most important features of any GIS software is related to its ability to analyze spatial data in different ways and with various functions. These functions are mad for different users. The most common function is called the proximity analysis function that could be used for finding answers for questions such as "what geographical features are near other features?" Such questions can be answered using a buffer to define the area of proximity, for example 0.5 kilometer, and then overlaying a second map layer containing the map features required [22]. To create a buffer, retailers should specify the source feature e.g. retail center and the buffer distance (e.g. $2 \mathrm{~km}$ ) and then GIS will draw a circle of a radius equal to the distance specified.

Proximity analysis can be applied at GIS based on straightline distance, distance cost over a network, or cost over surface. Each one of these types of GIS analysis can be applied in retail studies and can find answers to several questions including finding out how many customers are within a 20-minute drive of existing or new store site [29]. One way of defining and measuring how close a store to customers is by measuring the distance to that store. However, this distance can be measured using cost such as time rather than length. Mapping travel costs in GIS gives retail planners a more precise measure of what's nearby than mapping distance, but it required more data preparation and processing (ibid). This technique is going to be discussed in more detail at the GIS application section.

\section{METHODS}

Based on the above discussion, it can be said that GIS has different tools which can be used by retail developers and planners for the purpose of identifying and analyzing retail catchment area. This part of the study will concentrate on explaining how to use these tools for two exciting retail centers called Al-Dawly and Al-Mahmal center located in Jeddah city, Saudi Arabia. Based on the retail classifications that are presented at this study, these centers fall with the medium sized retail centers group. In order to define the catchment area of this selected centers, a GIS application is created which covers three main retail issues which are : adefining retail catchment area, b- building retail demand profile, and c- analysisng retail catchment area.

In order to build this GIS application, several data sets were collected and then entered into the ArcGIS software. These data fall into the three major vector data model types which are as following:

\section{A. Line data}

This type of data is stored in GIS as a series of ordered X, $\mathrm{Y}$ coordinates and the segments of a line can be straight, circular, elliptical or splined [27]. Road network of Jeddah 
city is an example of line data model that is created for the present study. This coverage has several attributes including road length, type and speed.

\section{B. Point Data}

GIS softwares store point data as single X, Y coordinate with several attributes. This type of data model is used in this study to represent location of retail center and retail customers. Several attributes are made with these data including center size, parking size, no. of shops and amount of GLA. For retail customer coverage the attributes are including district name and purpose of visits.

\section{Polygon data}

This type of features is modeled at GIS as a series of segments that enclose an area and form a set of closed area [27]. City districts coverage is an example of this type of GIS data that is created for the present study. This coverage includes attributes such as district name and area, and size of population and households for each district.

All of the above data were originally in a non-digital format. Therefore, manual digitizing and keyboard entry methods are used to convert all of these data into GIS digital formats (shape files and coverages). The next section will discuss the results of this GIS application that can be used by retail developers and planners of the selected centers.

\section{RESULTS}

\section{A. Defining retail catchment area}

There are several GIS methods that can be used for defining the primary catchment area of retail centers. The most common one is related to customers spotting. Several studies have used this type of GIS function for defining retail catchment and for demographic analysis [30, 31, 32, and 4] . For example, Jones et al, 1995 [4], have defined primary catchment areas for retail centers based on the nearest $60 \%$ of retail center consumers. In order to define the primary catchment area of Al-Dawly center, a survey is made on a sample of customers visiting this center. According to the records of this center the average amount of customers visiting the center is about 4500 customers per month. Unfortunately, there are no spatial records for each one of those customers. Therefore, a survey on $5 \%$ of the total customers is made to show the spatial distribution of the center demand. This data is used for the main objective of this part of the study that is defining the primary retail catchment area. The survey is made using a questioner that shows the address of customer, reason for visiting this center and the social economical background of each customer. All of the collected survey questionnaire are captured into the GIS using the address geo-coding function. This function use address information in the attribute table of a reference data (e.g. street network) to figure out where to locate address points [33]. The more detailed the reference data, the more accurately addresses can be located. The output of this function is either a shape file or a geodatabase having feature class of points with all the attributes of the address table, some of the attribute of the reference data and optionally some new attributes, such as the $\mathrm{X}, \mathrm{Y}$ coordinates of each point (ibid).
Once the location of retail customers is defined (Fig. 1), the following task was to select the nearest $60 \%$ of Al-Dawly customers. This was achieved using the following steps.

1) Query builder is applied on customer location shape file to select the nearest $60 \%$ of Al-Dawly customers.

2) The 'select by them' function of ArcGIS is used to define areas and districts that fall within the results found at step 1. In this case, ArcGIS selects city districts that intersect with the selected features of Al-Dawly customer shape file.

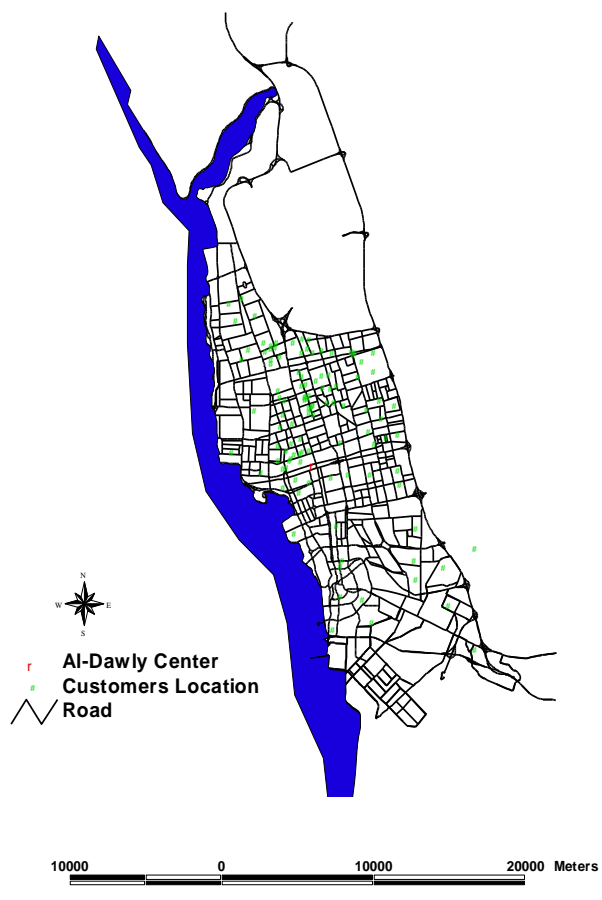

Fig. 1. Customer Distribution of Al-Dawly Center

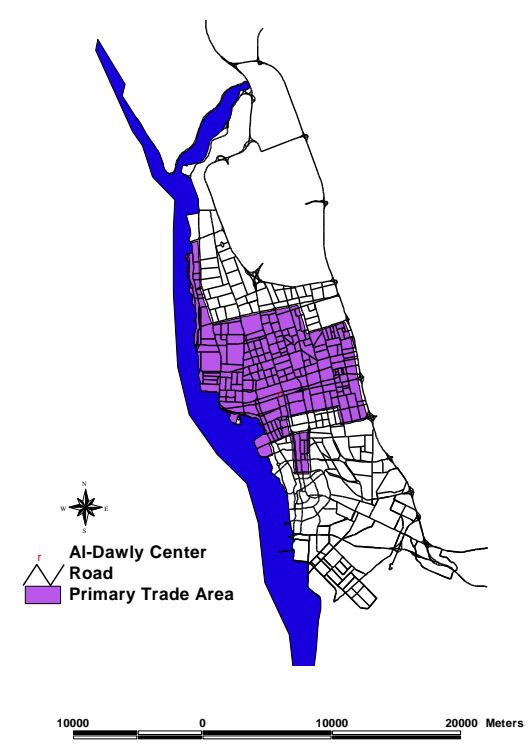

Fig. 2. Primary Trade area of Al-Dawly Center 


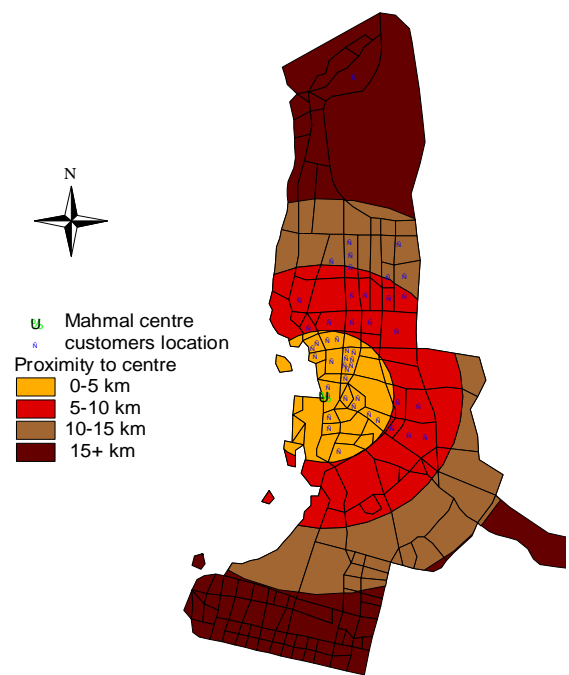

Fig. 3. Customers distribution of Mahmal center

The results of this step are saved into a new GIS shape file that show the city districts that form the primary catchment area of Al-Dawly center.

3) The results of step 2 are further manipulated using the 'Dissolve' function which is one of the Geoprocessing tool available in ArcGIS that can be used to remove the boundaries between adjacent polygons that have the same value for a specified attribute. This function is useful for example to create a GIS coverage showing sales regions by sales person where each sales person is responsible for several countries [27]. Fig. 2 shows the output of this step which describes the primary catchment area of Al-Dawly center (the total catchment is 826678 person) after removing districts shared boundaries. This catchment includes districts such as AlKhaldeyah at the west, Alsafa and Alrehab at the east, Al salamah and AlRabiyah at the north and Alandalus at the south of Al-Dawly center. One of the main uses of this catchment area is that it shows the city districts that are producing the major demand to this center and it also shows the parts of the city that are less attracted to this center e.g. Albalad district or Aljameah district. One of the main questions which retailers always ask is where customers are located? This question is important because by finding an answer to it, retailers can define their real catchment population and in the same time can have a clear view about the less attracted area for a certain centre. Accordingly, one of the first questions of the present study's survey is concerning the location of the customer's home. This data is converted into point coverage and plotted around each commercial centre. Knowing where customers are located is useful, but also how far they travel to the commercial centre is also another important issue, which has been included in this application. Accessibility zones have been buffered around each commercial centre and then over- layed with the customer location coverages to show the travel distance between centres and customers locations (Fig. 3).

The analysis of al Mahmal centre show that there is quite large number of customers how live in the 10-15 km and who are interested in visiting this centre. In addition to customers spotting technique, GIS software provide many useful tools which can be used by retail planners for defining retail catchment area. For example, ArcGIS software can define the following type of catchment/trade areas: radius.

a) simple ring - created around store using a specified

b) data-driven ring - created around store using a radius proportional to a store characteristic such as total sales, square footage, and GLA.

c) equal competition - creates trade area boundaries halfway between each store and its neighboring stores (Thiesen polygons).

d) drive time - defines areas accessible a long the street network based on a specified maximum travel time or distance.

e) gravity model - predicts the sales potential of an area based on distance competition attractiveness factors, and consumer spending.

f) threshold ring - creates rings containing a specified population or household count [34].

The drive time catchment area defines catchment area of any facility on a street network data based on the expected travel time to such facility. It is considered as useful technique for defining catchment area of emergency services where time to reach a location is very critical. One of the potential applications of this technique is related to retail centers which is considered by the presented paper.

In order to create a drive time model for Al-Dawly center, network analysis module of ArcGIS is used which facilitates the modeling of spatial networks and which can be used for determining efficient paths and travel sequences. The network data model of ArcGIS consists of network links, network nodes, stops centers and turns. The network links are modeled as arcs. Each arc in the network coverage can have what is called link impedance which is referred to the cost associated with traversing an entire network link [35]. Distance, time, money or combinations of all are examples of costs that can be used as linked impedance. The present study has calculated travel time along every network link of Jeddah city and save it at the impedance attributes file. This calculation takes into account different road speeds which varies according to road type e.g. major road has $80 \mathrm{~km}$ speed average and local road has $30 \mathrm{~km}$ speed average. The calculated time cost also takes into consideration the network traffic over major road which gives them higher cost than other road of Jeddah city.

Once time to travel is calculated for every arc and saved as an impedance item, the following step was to decide about the desired travel time to Al-Dawly center. Based on the retail catchment area review, this center falls with the 20 minutes drive time retail types. Accordingly, a 20 minutes drive time catchment area is created and presented at Fig. 4. This output 
defines the total catchment area of Al-Dawly center and the same technique can be applied for all other retail centers located at Jeddah city including Al-Mahmal center.

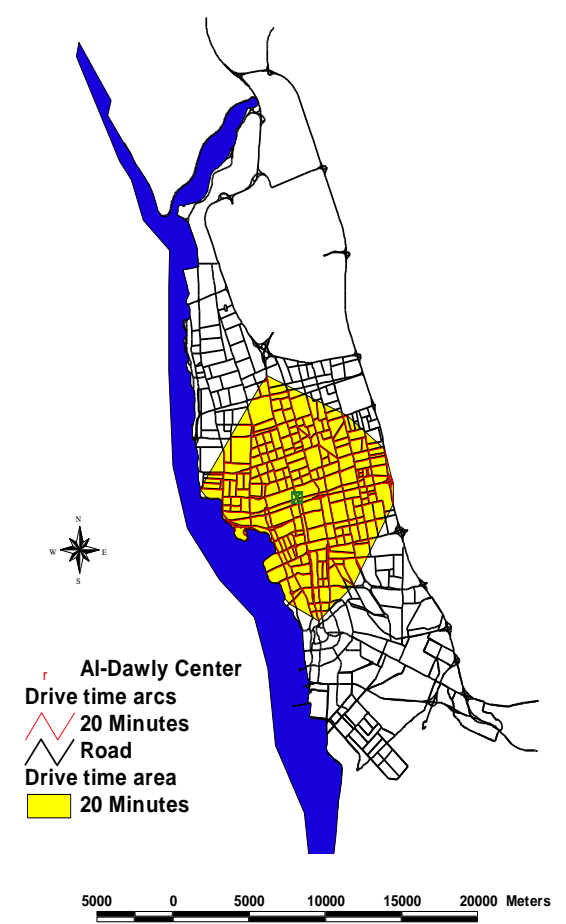

Fig. 4. A 20-minutes Drive time Trade area
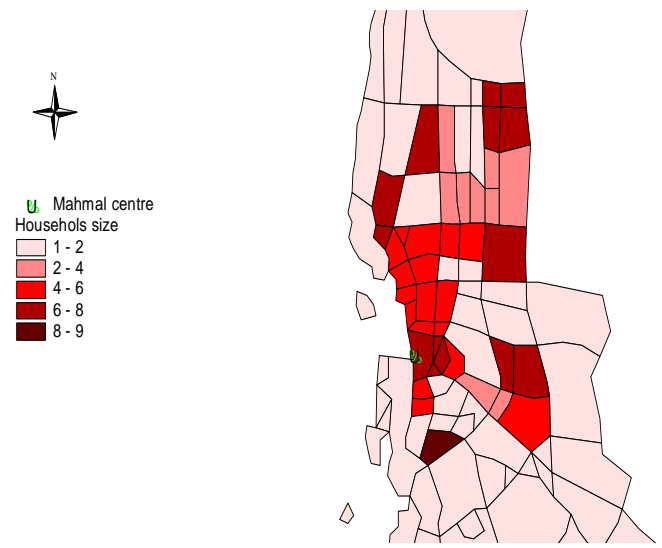

Fig. 5. Household size of Mahaml customers
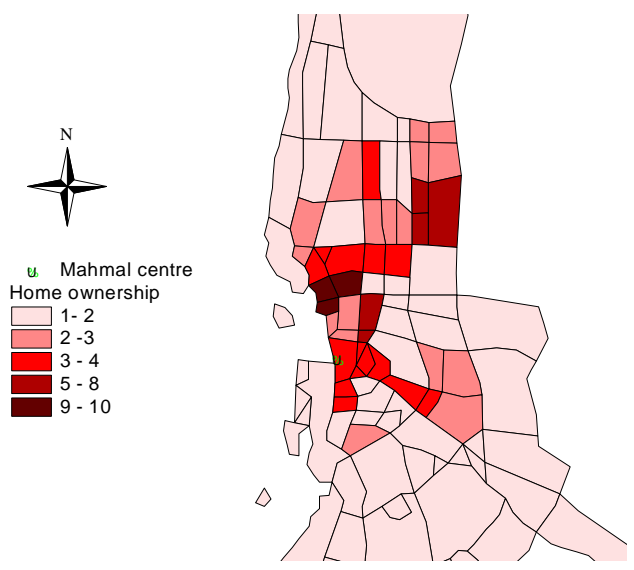

Fig. 6. Home ownership for Mahaml customers

\section{B. Building retail demand profile}

Retail customers profile is useful for retailers because it gives them the opportunity of knowing who are their customers? By doing so, retailers can approach certain customers for a specific retailing purposes. Jonsek and Simmons, 1991 [36], have mentioned that once the centre catchment area is drawn then analyst tries to identify the customers profile for such areas. The present study has created customers profile for al Mahmal shopping centre, which includes data regarding income, age - sex status, age, homeownership, car ownership, purposes for visit as well frequencies of visiting such shopping centre. This large profile is very useful for retailers because it shows the actual demand characteristics. The collected survey data can be divided into two categories, which are the demographic profile and the demand profile. The former includes information about income, age-sex, household size, education level, and housing ownership. The later has information about the purpose of visit (i.e. to pay certain goods or for general shopping) reasons for selecting the shopping centre (i.e. close to home, low prices, free parking etc), and frequent of visits. The present study has selected two demographic data (household size and home ownership) and one demand-status data (visits to centres). The spatial distribution of household size and home ownership for al Mahmal centre is shown in Figures 5 and 6. The results of these figures show the existing demand status of the shopping centre. They are very useful in identify a clear image about the types of customers in each shopping centre. In addition, such profile is of great value to retail developers

One of the possible GIS applications in retail studies is related to identifying the location of potential target markets. For example, GIS can be used to define the spatial distribution of one customer sequent such as middle-income customers, large size families or families with large children numbers. This type of GIS-based retail analysis can be used for:

a) evaluating the potential of new tenants serving a particular market niche, 
b) providing marketing advice to existing retail tenants that do not have the skills or technology to undertake detailed geo-demographic analysis, and

c) identifying market/lifestyle segments that the shopping center is under-serving [2].

The collected data about Al-Dawly center customers cover several social and economical information about those customers that can use for the purpose of target market identification. One example of this type of analysis is to identify location of households that own houses. This type of customers can be seen as middle-to-high income customers that can be reached for promoting certain goods or services available at Al-Dawly center (e.g. electronic products). Fig. 7 presents the spatial distribution of house owners' customers as well as tenants customers. One of the main findings of this output is that house owner customers of this retail center are concentrated at the western city districts; meanwhile tenant customers are located mainly at the eastern city districts.

The present study has used Intersect function (which is on of GIS overlay analysis functions) with the drive time model to identify the potential demand of Al-Dawly center. It was found that there is 208,163 households live within the retail center drive time catchment area. Fig. 8 defines classification of total households that are living within the resulted drive time trade area. It also identifies the spatial distribution of all households that are considered as potential customers for AlDawly center.

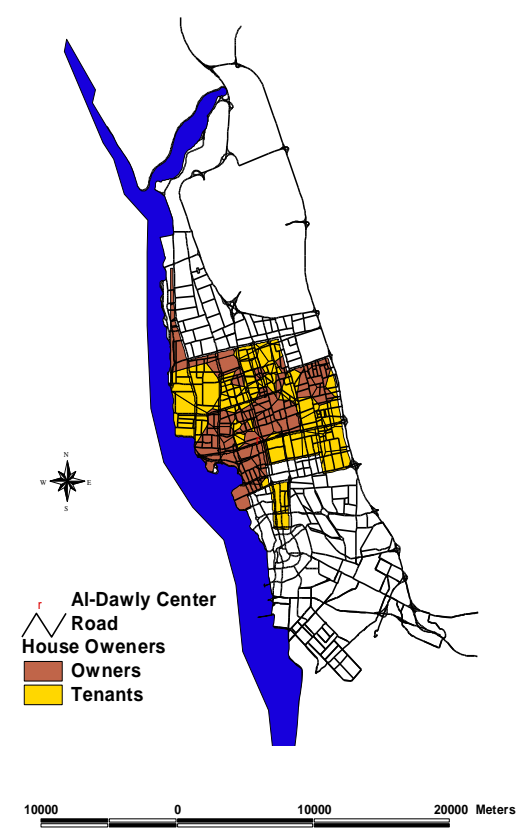

Fig. 7. Location of House owners Customers

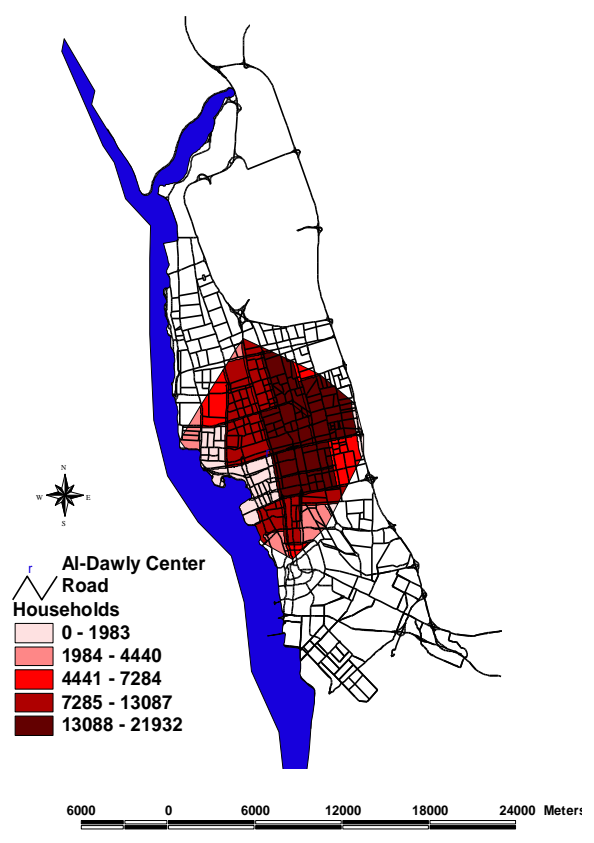

Fig. 8. Spatial distribution of households living inside retail trade area

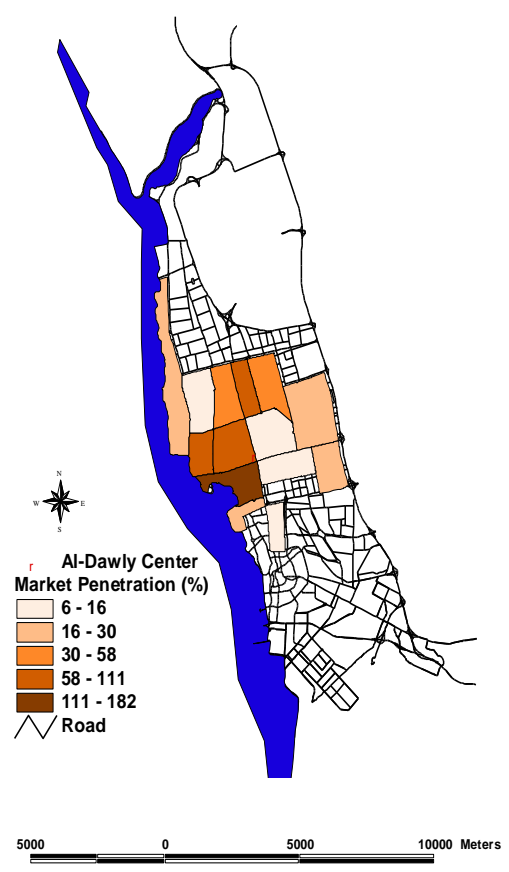

Fig. 9. Market Penetration for Al-Dawly retail center 


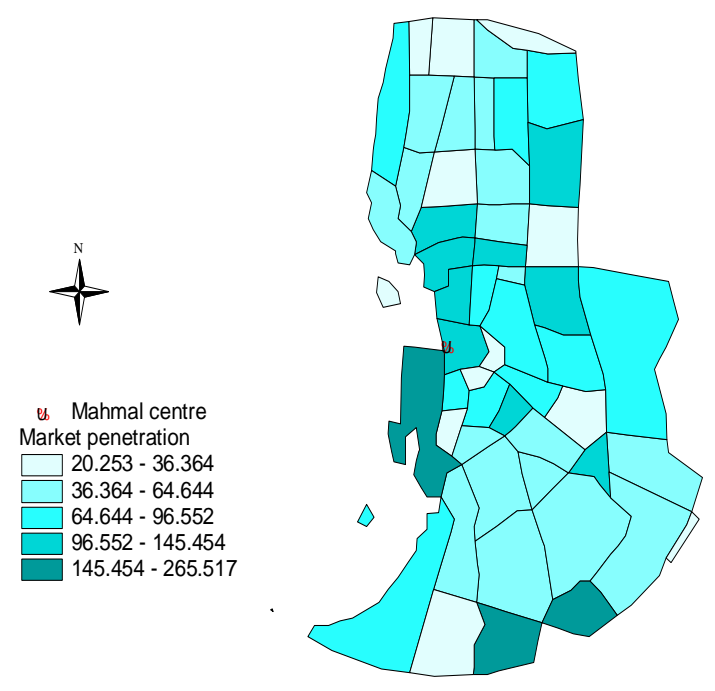

Fig. 10. Market penetration for Mahmal centre

\section{Analyzing retail catchment areas}

Market penetration is referred to the analysis of retail center demand in relation to the total demand of retailing at any location. It is a term that was developed to permit businesses to know what percentage of all possible sales were represented by their actual sales. In common practice, one measures market penetration by measuring all real sales of a given good for a given period and then comparing that total with the total of all sales of that specific good. Based on this definition, the real sales are referred to the measured size of customers at every city district, and the total sales are referred to the total potential retail customers at every district. The presented study has applied this technique to identify the market penetration of Jeddah shopping centres. The calculation of market penetration is reached using the following formula:

$\mathrm{MPa}=\mathrm{SCa} / \mathrm{SCn}$

Where:

$$
\begin{aligned}
& \mathrm{MPa}=\text { Market penetration for centre } \mathrm{a} \\
& \mathrm{SCa}=\text { Shopping customers for centre } \mathrm{a} \\
& \mathrm{SCn}=\text { Total shopping customers for centres } \mathrm{n}
\end{aligned}
$$

The present study has defined the market penetration of Al-Dawly retail center at the city district level. Here, the number of customer points allocated to any district is divided by the number of households in each respective district. This value was then manipulated by 100 to provide a standardized market penetration index. The resulting index helps retail planners to examine the degree of market share in various districts and can relate such variations in the share to other factors such as strength of the competition or retail accessibility. Fig. 9 presents the output of the GIS based market penetration of Al-Dawly center. This output indicates that there are some districts which are close to this center, such as Alfaysaleyah and Alazizeyah, but not producing high demand to this center. One of the possible reasons for this scenario is the competition resulted from centers located within these districts. The same results are also found at Alrehab and Alsafa districts. However, Alandalus district is considered as one of the main demand areas of Al-Dawly center. This district when compared with its total households produces a remarkable demand to Aldawly center. In addition to that district, Alkhaldeyah and Alrawdah are another two important demand locations that also produce more customers to Aldawly center. The same technique was applied for al Mahmal centre, and the results show that there are areas of good and poor performance (Fig. 10). For example, alMahmal is performing well at the north and at the city centre, however, it has a scattered low performance at different city districts. The results of these models can be use by shopping developers to get more customers from areas with low performance. Such areas should have the priority in the shopping marketing policy in order to increase the centres demand.

\section{CONCLUSION}

This paper has classified retail centers into three main types based on their sizes and their actual catchment area. Large centers have about 800,000 person catchment, medium centers have about 200,000 person and small centers serve about 150,000 person. Two retail centesr called Al-Dawly and Al-Mahmal center were selected as a case study, and GIS is used to model the catchment area of these centers. Two main types of catchment area are produced. The first one is created based on the actual distribution of retail customers. The output of this step is used to define the market penetration of the selected center. It is founded that there are some city areas that fall within the center catchment area but producing low demand. There areas should be reached first by retail developers to find out the reasons for not producing high demand to this center. The second type of catchment are model is created based on drive time technique. This model is useful for defining the expected total population that would visit retail centers.

\section{REFERENCES}

[1] M. Birkin, G. Clarke G, M. Clarke M, and A. Wilson, 1996, Intelligent GIA, Geoinformation International, Cambridge.

[2] K. Jones, M. Pearcc and M Biasiotto, 1995, The Management and evaluation of shopping center mall dynamics and competitive positioning using a GIS technology, Journal of Shopping Center Research, Vol.2, No2, 49-82.

[3] M. Birkin, G. Clarke G, and M. Clarke M, 2002, Retail geography \& intelligent network planning, Wiley, Chichester.

[4] A. Murad, 2003, Creating a GIS application for retail centers in Jeddah city, International Journal of Applied Earth Observation and Geoinformation, Vol4, No.4, 329-338.

[5] A. Murad, 2005, Using Geographical Information Systems for Exploring Demand on Retail Centers at Jeddah City, The Second IEEE Conference on Service Systems and Service Management, Chongqing University, China.

[6] Johnes C., 1969, Regional Shopping Centres, Business Books Limited, London.

[7] Dawson J., 1983, Shopping Centre Development, Longman, London.

[8] Guy C, 1980, Retail Location and Relative Planning in Britain, Gower, London.

[9] Gosling D. and Martland B., 1976, Design and Planning of Retail Systems, Architectural Press, London. 
[10] ICSC, 2003a, New Large Centers: Tres Aguas, International Council of Shop ping Centers, New York.

[11] ICSC, 2003b, New Large Centers: Carre Senart, International Council of Shopping Centers, New York.

[12] ICSC, 2003c, New Large Centers: Bonaire, International Council of Shopping Centers, New York.

[13] ICSC, 2003d, New Medium-sized Centers: Spandau Arcaden, International Council of Shopping Centers, New York.

[14] ICSC, 2003e, New Medium-sized Centers: Atmarkt Galerie, International Council of Shopping Centers, New York.

[15] ICSC, 2003f, New Medium-sized Centers: Fiumara Centro Cmmerciale, International Council of Shopping Centers, New York.

[16] ICSC, 2003g, New Small Centers: Centre Commercial Les Passages, International Council of Shopping Centers, New York.

[17] ICSC, 2003h, New Small Centers: Espace Jaures, International Council of Shopping Centers, New York.

[18] k. Jones \& J. Simmons, 1991, The Retail Environment, Rortledge, London.

[19] P. Brown , 1991, Geodemogrsphics: a review of recent developments and emerging issues, in Masser I and Blakemore M (Eds), Handling Geographic information, [36] Longman, London, 221-58.

[20] Y. Chou, 1997, Exploring spatial analysis in geographic information systems, Onward press, Santa Fe.

[21] M. Charlton, L. Raol, and S. Laiuer, 1995, GIS and the census, in Openshaw S (Ed), Cnsus user's handbook, Geoinformation international, Cambridge, p.p. 134-160.

[22] D. Grimshaw, 2000, Bringing geographical information systems into Business, John wiley and sons, New York.
[23] S. Dibb, and J. Simkin, 1991, Targeting, segments and positioning, Intenational Journal of retail distribution and management, 19(3),4-10.

[24] IKEA, 1992, The IKEA world 92/93, Humlebaek, Denmark.

[25] P. Sleight, 1995, Neighbourhoodwatch Geodemographic and Lifestyle Data in the UK GIS Market Place, Mapping Awareness, Vol. 9, No. 6, pp. 18-21.

[26] P. Longley, and G. Clarke, 1995, GIS for Business and service Planning, Geoinformation international, Cambridge.

[27] ZEILER M, 1999, Modeling our World: The ESRI Guide to Geodatabase Design, ESRI, Redlands.

[28] B. Booth, 2000, Using ArcGIS 3D Analyst, ESRI, Redlands.

[29] A. Mitchell, 1999, The ESRI Guide to GIS Analysis Volume 1: Geographic Patterns \& Relationships, ESRI, Redlands.

[30] C. Reid, 1993, Vertical Industry Applications: Retail Trade, In Castle G.H. (ed), Profiting from a Geographic Information System, GIS World Books, Colorado, 131-151.

[31] C. King, 1993, Vertical industry applications: Financial institutions, In Castle G.H. (ed), Profiting from a Geographic Information System, GIS World Books, Colorado, 57-74.

[32] T. Moloney, T. Lea and C. Kowalchuk, 1993, Vertical Industry Applications: Manufacturing and Packaging Goods, In Castle G.H. (ed), Profiting from a Geographic Information System, GIS World Books, Colorado, 105-129.

[33] T. Ormsby, E. Napoleon, R. Burke , L. Feaster, and C. Groessle, 2004, Getting to Know ArcGIS Desktop, ESRI, Redlands.

[34] ESRI, 2004, ArcGIS Business Analyst, ESRI, Redlands.

[35] ESRI, 1992, Network Analysis, ESRI, Redlands.

[36] Jones K. \& Simmons J., 1991, The Retail Environment, Rortledge, London. 